\title{
Conflicto y organización sindical en los origenes del peronismo: la conformación de la Asociación Obrera Textil
}

\author{
Marcos Schiavi \\ UBA
}

\section{Introducción}

El proceso abierto en junio de 1943 con el golpe de Estado terminó ubicando al movimiento sindical, tres años después, en un lugar de poder que nadie había osado imaginar un tiempo antes, ni siquiera sus mismos dirigentes. Los sindicatos se habian convertido, luego de las elecciones de febrero de 1946, en el principal actor de la fuerza política gobernante. Juan Domingo Perón, por su parte, se encontró dirigiendo una fuerza en la que los trabajadores tenían un peso abrumador, algo que no estaba en sus planes originales.

Es innegable que la llegada de Perón al poder fue una bisagra en la historia organizacional del sindicalismo argentino. Apoyados por su gobierno, en apenas unos meses, se crearon decenas de nuevos sindicatos, la mayoría industriales. La consolidación de estas organizaciones ocurrió en los primeros treinta meses de su gobierno, aquellos que van desde junio de 1946 hasta fines de 1948. Por fuera de la innegable injerencia estatal, este proceso se dio en base a altos niveles de sindicalización y a una fuerte movilización obrera, los cuales derivaron en un rápido desarrollo organizativo. Esta coyuntura limitó el desarrollo posterior del movimiento obrero y del propio gobierno peronista (Torre, 1990; Doyon, 2006).

En este período, el número de afiliados a los sindicatos se triplicó: pasó del medio millón al millón y medio. El mayor crecimiento se produjo en la industria. Allí, en 1945, había algo más de doscientos mil afiliados. Tres años después, rozaban los ochocientos mil. Esto alteró la relación de fuerzas internas del movimiento sindical, ya que la Unión Ferroviaria, aunque continuó siendo el sindicato más grande, comenzó a tener un contrapeso en las nuevas organizaciones industriales. El Estado apoyó esta sindicalización, pero esto no la explica completamente; para eso, es necesario reflexionar sobre el alto nivel de movilización obrera. 
Entre 1946 y 1948, sólo en Buenos Aires, hubo cerca de trescientas huelgas, con más de un millón de huelguistas y ocho millones de días perdidos (Doyon, 2006: 252-275). Este gran aumento sólo era comparable con el ocurrido diez años antes, en 1935-1936 (Iñigo Carrera, 2000). Pararon trabajadores de la carne, azucareros, panaderos, textiles, metalúrgicos, petroleros, obreros de la construcción, del transporte, portuarios, municipales y bancarios, entre otros. Esta movilización obrera no sólo impuso mejoras salariales. También impulsó una legislación social paralela, superior a la implantada por el gobierno, pues, a partir de los convenios colectivos, se conformó un cuerpo legal amplificador del espíritu de la normativa general. Hubo, además, una innegable redistribución del poder en los lugares de trabajo. El gobierno, por su parte, no apoyaba automáticamente cualquier huelga; tampoco sostenía cualquier reivindicación. Se encontraba siempre más predispuesto a negociar las demandas salariales que a tratar reclamos acerca del control sobre el proceso de trabajo; intentó contener estos últimos, aunque sin mucho éxito.

La conflictividad industrial impactó, por un lado, a nivel organizativo: fue determinante en la conformación de los nuevos sindicatos industriales. Por otro, en la relación capital-trabajo: los conflictos y victorias obreras del periodo transformaron condiciones a nivel planta y a nivel rama. Esta dinámica sindical donde se entrelazaban cuestiones vinculadas a la movilización y organización de los trabajadores se dio en la mayoría de las actividades industriales; allí, a nivel rama, y no en las superestructuras cegetistas, es donde se puede aprehender el proceso.

En este punto, es necesario reconocer que han sido mútiples los estudios que indagaron sobre la relación peronismo-sindicatos; en particular, sobre la existente en sus origenes. Pero que, sin embargo, aún resta mucho por conocer sobre la dinámica sindical a nivel rama. Tradicionalmente, al analizarse este periodo, se ha tomado en cuenta sólo el papel de la Confederación General del Trabajo (CGT) (Del Campo, 1983; Gambini, 1999; Germani, 1962; Little, 1979). Poco se ha examinado el rol de los sindicatos de rama, y sus relaciones con las bases movilizadas, las cámaras empresarias, la central obrera y el gobierno. Este artículo busca ser un aporte en este sentido; se propone alcanzar una mayor comprensión de la dinámica entre conflicto y organización esbozada arriba a partir del estudio del caso textil en Buenos Aires y sus alrededores.

En la Argentina peronista, el lugar de la industria textil y de las organizaciones que nucleaban a sus trabajadores fue nodal. Su lugar en los niveles de empleo y de actividad en la economía eran muy importantes entonces (Villanueva, 1972; Belini, 2009). Por eso la relevancia de su estudio y el peso relativo del caso en relación a la industria en general. 
Además, y más allá de estas cuestiones estructurales, el propio devenir de la movilización obrera textil es de gran utilidad para aprehender la dinámica sindical de la coyuntura.

A comienzos del gobierno, ni la Asociación Obrera Textil (AOT) ni ninguna otra organización obrera tenía el poder necesario para controlar la alta conflictividad que protagonizaban las comisiones internas y los sindicatos autónomos por empresa. Tanto para el gobierno como para la patronal, era necesario establecer rápidamente una regulación del conflicto que dotara de previsibilidad el ritmo de producción textil. Para lograrlo, el primer paso era conformar un sindicato único y poderoso que acordara salarios y condiciones de trabajo estables. Era imperioso canalizar la movilización social que el triunfo peronista había generado. Por eso, la apuesta gubernamental fue empoderar y asentar en el gremio a la joven AOT.

En 1946 y 1947, esta preocupación gubernamental convivió con la multiplicación de los conflictos obreros textiles. Pese a que las negociaciones se efectuaban por rama (algodón, lana, medias, etcétera), una parte importante de esos conflictos se desarrolló por empresa. Este tipo de movilización, donde la lucha específica en un establecimiento tenía un peso muy alto a nivel general, fue una de las particularidades del caso textil en los primeros tiempos peronistas. Progresivamente, sobre todo a partir de la intervención de fines de 1947, las distintas dirigencias sindicales textiles buscaron controlar esto.

En este artículo comenzaremos analizando los antecedentes, conformación y primera organización de la AOT. Luego nos centraremos en tres casos relevantes del periodo 1946-1947: Sudamtex, Argos y Alpargatas, ${ }^{1}$ para concluir describiendo brevemente el proceso de normalización y canalización del conflicto textil.

\section{Los sindicatos textiles y las comisiones internas antes de la AOT}

Como introducción necesaria al tema elegido se debe considerar las herencias y organizaciones previas y el desarrollo de la militancia fabril. Esto nos permitirá observar las rupturas y continuidades del movimiento obrero textil a partir de la llegada de Juan Perón a la presidencia de la Nación.

1. Nos hemos centrado en estos casos por distintas razones. Sudamtex se debe a que fue allí donde se dio la primera huelga de magnitud encabezada por la AOT. Argos es relevante por ser el caso que muestra más claramente las tensiones intersindicales existentes al interior del gremio textil. Alpargatas, por último, se justifica por su volumen (más de diez mil trabajadores) y su influencia en el gremio en general. 
La organización más sistemática del gremio textil se inició a comienzos de los años 20 con el establecimiento de la Federación Obrera Textil (FOT). Es importante detenerse aquí y resaltar el tipo de estructura que se dio originalmente el gremio: la federación. Sin duda, esto se debía a que en él habían proliferado múltiples sindicatos por empresa, factor que no podía desestimarse. Mientras que en metalúrgicos la problemática había sido la unión de los distintos oficios, aquí el eje era la disgregación sindical en empresas.

Durante un primer período, convivieron en la FOT militantes comunistas y socialistas, hasta que, a fines de 1929, luego de una asamblea no reconocida, se quebró el sindicato: los socialistas se mantuvieron en la FOT, mientras que los comunistas crearon la Federación Obrera de la Industria Textil (FOIT) (Camarero, 2007).

En 1934, la socialista FOT cambió su nombre por el de Unión Obrera Textil (UOT). Dos años después, se disolvió la FOIT y los comunistas se sumaron a la UOT. Esta última decisión era coherente con la propuesta comunista de conformar sindicatos únicos por rama industrial y con el inicio de su política de participación en frentes populares. La incorporación de los comunistas a la UOT duplicó el número de afiliados que, para entonces, se acercaba a los cuatro mil (Di Tella, 1993).

En 1939, los comunistas tomaron el control de la UOT, con Jorge Michelon como secretario general, lo que generó una nueva división. Los socialistas, entre quienes se destacaban Cándido Gregorio, Lucio Bonilla y Juan Pardo, formaron en 1941 una UOT rival, con sede en la calle Independencia, y la anterior continuó funcionando en la calle Entre Ríos. Luego de la escisión, el dominio de los socialistas se redujo a la rama cotton y medias circulares, y a otros pocos establecimientos. Hasta por lo menos 1943, la UOT comunista se mantuvo como el sindicato más importante del gremio textil.

Sin embargo, el golpe de junio de 1943 implicó un fuerte impacto para los sindicatos comunistas. Las primeras medidas oficiales del gobierno militar estuvieron dirigidas, precisamente, a hostigarlos. En el caso textil, fueron arrestados y encarcelados muchos militantes de importancia; algunos pocos, entre ellos, Jorge Michelon, su secretario general, lograron ocultarse. Por su parte, el sindicato textil socialista tuvo, desde un comienzo, una buena relación con el gobierno militar. Sus principales dirigentes se reunieron con el ministro del Interior a poco de su asunción. Ese acercamiento inicial se profundizó cuando la Secretaría de Trabajo y Previsión (STyP) comenzó a apoyar directamente a la UOT socialista, sostén que se tradujo en un mayor alcance y número de afiliados logrados en apenas unos meses. Sin embargo, y pese a lo beneficiosa que le había resultado la relación, en septiembre de 1945, siguiendo directivas del Partido Socialista (PS), el sindicato se 
retiró de la CGT y rompió definitivamente los vínculos políticos con el gobierno (Del Campo, 2005).

Al romper con la STyP, la UOT socialista perdió rápidamente la centralidad obtenida. Volvió a ser la pequeña organización que era a comienzos de 1943. Le debía al gobierno más de lo que los socialistas estaban dispuestos a reconocer (Horowitz, 2004).

De su seno nació la Asociación Obrera Textil: sus fundadores habian participado en paritarias en nombre de la UOT socialista meses antes de romper y crear una nueva organización.

Un factor necesario y clave de este desarrollo sindical precedente fue la organización en los lugares de trabajo. En ese sentido, la reciente tesis de Diego Ceruso ha significado un avance sustancial en el estudio de las comisiones internas, pues en ella ha demostrado que éstas ya se encontraban presentes en las estructuras de representación gremial de base impulsadas en los sindicatos de la construcción, textiles y metalúrgicos a partir de 1936. Contradiciendo la idea de Doyon de que las comisiones internas existentes eran fomentadas por las empresas, Ceruso constata que habian sido impulsadas por el PC e integradas a la estructura del sindicato para defender los intereses de los obreros en cuestión (Ceruso, 2010). Según el relevamiento realizado por este autor, entre 1936 y 1943, existieron comisiones internas en las textiles Grafa, Salzman, Piccaluga, Manufactura Algodonera Argentina, Gratry, Ducilo y Danubio. Aunque muchas veces su vida era breve, Manufactura Algodonera y Ducilo fueron, en ese sentido, la excepción.

Entre 1936 y 1943, las comisiones internas se encontraban en un proceso inicial de desarrollo, fueran metalúrgicas o textiles. Exhibian características comunes: ejercian la representación de los obreros frente a las empresas y patrones; eran designadas por la asamblea del personal; intentaban controlar las condiciones laborales; y buscaban su reconocimiento legal. Estos organismos eran perseguidos por la patronal y por el Estado, quienes pronto comenzaron a dar forma a una política particular hacia ellas.

Lejos de ser un elemento propio del modelo sindical peronista, las comisiones internas le fueron impuestas en el fluido proceso abierto primero en junio de 1943 y luego en octubre de 1945.

\section{La organización de la Asociación Obrera Textil}

La AOT fue fundada el 27 de octubre de 1945 en el sótano de la Unión Tranviaria Automotor en Moreno 2900 (Buenos Aires). Integraron su primera comisión directiva Mariano Tedesco (secretario general), Lucio Cano (secretario adjunto), José Grioli (secretario administrativo), Enrique Galliero (tesorero) y Antonio Ciurlande (protesorero). Estos jóvenes 
la convirtieron en apenas unos meses en el sindicato textil más importante de la Argentina. En octubre de 1946, ya tenía sesenta y cinco mil afiliados. ${ }^{2}$ No lo hicieron solos: para alcanzar ese objetivo, contaron con un fuerte apoyo del gobierno peronista.

Sin embargo, y aun contando con esa ayuda, llevar a cabo esta tarea implicó enfrentar tres grandes desafios. En primer lugar, el elemento ideológico. La AOT era un sindicato de carácter apolítico (su dirigencia estaba influenciada por la corriente sindicalista) que se proponía organizar un gremio donde el comunismo y el socialismo tenian una importante ascendencia sobre la militancia de base. En segundo lugar, la descentralización de la conflictividad. Para consolidar la organización, era imperioso fortalecer la dirección y reglamentar las funciones de las instancias intermedias del sindicato (comisiones de rama y comisiones internas). En tercer lugar, la competencia con otros sindicatos. La AOT no era la única organización cercana al gobierno, sino que convivia con distintos sindicatos en la actividad.

Aunque determinante en su consolidación, el apoyo del gobierno era también un problema por resolver para la dirigencia textil. En octubre de 1946, en su órgano oficial, la AOT explicitó cuál era entonces su posición política:

Se dio a nuestra Asociación el carácter apolítico que le correspondía, repudiando abiertamente a los gobiernos inhumanos, oligárquicos y antiargentinos, apoyando, con las fuerzas legales de la agremiación y la justicia social y con el caudal humano de las masas oprimidas, a los gobiernos obreros y argentinistas, no persiguiendo con eso, un fin político, sino, la independencia moral y material de la Patria.

No nos situaremos a la sombra de ninguna bandería política, porque consideramos que es dentro de la más absoluta prescindencia ideológica como se debe crear y defender el verdadero sindicalismo para no contrarrestar su fuerza autonómica. ${ }^{3}$

La línea sostenida era la del sindicalismo: la centralidad estaba puesta en la organización y movilización obrera por encima de partidos y líderes. En un discurso dado el 11 de octubre de 1946, Tedesco afirmó:

Amigos: Somos hijos de nosotros mismos. Somos hijos de nuestro propio dolor y de nuestras propias esperanzas. Los peronistas no somos obra de ningún partido y de ningún po-

2. AOT. (Recordemos lo pasado. Unirse y trabajar para que no se repita.) Órgano oficial de la AOT, año $1, \mathrm{~N}^{\circ} 1$, octubre de 1946.

3. Ídem. 
lítico. [...] Ahora les salen muchos dueños del 17 de octubre, pero la verdad es una sola, la verdad, es que en aquella jornada no hubo más dirigente que la lealtad popular que no traiciona nunca a quien no la engaña, y que estuvo con Perón porque Perón nunca había engañado a su pueblo.

El sindicato en lugar del comité; el sindicato, sin interferencias de políticos, como única manifestación de la voluntad popular. $^{4}$

La última de estas afirmaciones, la idea del sindicato como única manifestación de la voluntad popular, estaba en las antípodas del pensamiento de Perón. El desplazamiento de Tedesco a comienzos de 1947 y la asunción de Lucio Cano como secretario general pudieron haber descomprimido esta situación. Sin embargo, la intervención del sindicato de octubre de 1947 demostró que los problemas del gobierno con la AOT no estaban resueltos.

Meses antes de su renuncia, Tedesco había logrado darle cierta organización interna al sindicato. Se habían conformado filiales en Avellaneda, Belgrano, Dique Luján, 4 de Junio, Jáuregui, Moreno, Patricios, Ramos Mejía, San Martín, Villa Lugano, Vicente López, Valentín Alsina, Villa Domínico, Rosario y Morón. Salvo la de Rosario, todas las demás se situaban en Buenos Aires y sus alrededores. Además, y como reflejo sindical de la naturaleza de la negociación colectiva textil, se establecieron comisiones de rama: algodón (dirigida por José Mujica); lana (dirigida por Norberto Framini); $;^{5}$ seda; tintorerias industriales; bolsa; cotton y circulares; cáñamo, yute, sisal y formio; tejido de punto; cintas y elásticos.

Estas comisiones de rama tenían un reglamento estatutario que, entre otras cosas, establecía que sobre el total de sus miembros debía haber un $70 \%$ de argentinos; indicaba que debian ser elegidos en asamblea ordinaria de secretarios de comisiones internas; que en los pedidos de mejoras, paros y huelgas, debian consultar con el consejo directivo, que se reservaba el derecho de intervenir en cualquier momento la comisión de rama.

Las comisiones internas también tenían un reglamento estatutario, cuyo objetivo principal era imponer un mayor control de la dirigencia sobre ellas. Al desarrollarse y ser reconocidas las organizaciones de base, el nuevo desafio que se les presentaba a los sindicatos era cómo regular su funcionamiento para evitar conflictos inorgánicos. Durante el peronismo, el reiterado pedido empresario de que se reglamentaran

4. Ídem.

5. Andrés Framini era, por entonces, secretario adjunto del Sub Consejo Directivo de Valentín Alsina. 
las comisiones internas hizo presuponer la inexistencia de ese tipo de controles. Distintos autores niegan o desconocen la existencia de tal reglamentación (James, 1981; Doyon, 2006). Daniel James, por ejemplo, sostiene que "no existía en los contratos ninguna especificación detallada concerniente a la índole de la representación sindical, sus formas o sus poderes" (James, 1981: 334). Sin embargo, en los casos que hemos estudiado, la situación es diferente. Tanto el sindicato metalúrgico (Schiavi, 2012) como el textil se dieron una reglamentación interna tempranamente, en 1946.

El reglamento textil establecia que las comisiones internas tenían totalmente prohibido hacer propaganda politica dentro de la planta y debian consultar con las comisiones de rama cualquier situación que implicara pedidos de mejoras, paros, huelgas y sanciones a obreros afiliados. Con este documento, la dirección de la AOT buscaba canalizar la movilización de sus bases. Un ejemplo de esto era el artículo 23:

De ninguna manera deberá pensar o dejar que un obrero así lo piense que el hecho de estar defendidos por esta Asociación ante los poderes públicos les da el derecho de estar continuamente en pugna con el establecimiento y considerar graves a hechos que pueden ser simples. ${ }^{6}$

El sindicato no se oponía a las comisiones internas, pues lo fortalecía como organización, pero al mismo tiempo, buscaba ajustar sus controles, lo que era también necesario para su afianzamiento. La actividad sindical en la fábrica legitimaba la presencia de la AOT mientras ésta les aseguraba protección a las comisiones internas. Como bien lo dice David Montgomery, esta militancia en las fábricas no podría haber adoptado una forma abierta y crónica sin contar con defensas sindicales y legales: "Para comprender y apreciar la importancia de las luchas en el centro de trabajo debe tenerse en cuenta toda la red de controles sociales que lo rodean" (Montgomery, 1985: 194). En síntesis, ambos se necesitaban. Cuán conflictivo era el vínculo dependía de factores políticos y de relaciones de fuerza.

La organización que se dio el sindicato necesitaba de la movilización obrera pero también de su control. La AOT utilizó los conflictos por empresa para ir fortaleciéndose. Debemos recordar que poseía una estructura muy débil a comienzos de 1946 (tenía apenas dos meses de existencia). Más allá del apoyo que le dio el gobierno, la dirigencia de la AOT debió ir armando un entramado de alianzas en distintas fábricas, sobre todo en la ciudad de Buenos Aires y sus alrededores, para poder 
imponerse como sindicato mayoritario. Se construyó a partir de las organizaciones de base y no al revés.

\section{Sudamtex y el asentamiento de la AOT}

La primera gran huelga donde la AOT tuvo una presencia destacada fue la del personal de Sudamtex, empresa norteamericana en la que se desempeñaba la mayoría de los fundadores de la asociación. En esta fábrica trabajaban cerca de cuatro mil obreros. Su importancia, la coyuntura política y sindical, más el origen del capital de la empresa hicieron que el apoyo a la medida fuera unánime en la prensa peronista y comunista. ${ }^{7}$

El conflicto comenzó el 12 de mayo de 1946, fecha en la que se realizó una asamblea de todo el personal de Sudamtex para considerar el convenio sobre mejoramiento económico y condiciones de trabajo presentado a la empresa. Mariano Tedesco explicó allí cómo en reiteradas ocasiones se había intentado obtener su aceptación sin ningún éxito. Ante esto, la asamblea decidió declarar la huelga en reclamo del cumplimiento estricto del trabajo a destajo, la humanización de las tareas y aumentos de salarios.

Lanzada la medida de fuerza, la AOT dio a conocer una resolución por la que pedía al personal de las demás fábricas de la industria textil que no adoptaran ninguna medida en favor de los compañeros de Sudamtex. El sindicato no tenía ni las fuerzas ni las herramientas organizativas necesarias para lanzar una acción general que pudiera controlar.

Luego de un mes de huelga, con las negociaciones empantanadas, El Laborista tituló: "La irreductible intransigencia patronal impone la intervención de la Sudamtex". ${ }^{8}$ En el petitorio presentado por la comisión interna, se solicitaba la disminución de telares para los tejedores, el escalafón, el reajuste del trabajo a destajo, la mensualización de los mecánicos y las jornadas de seis horas para la sección cardas.

Ante esto, la patronal se mantenía firme; llegó incluso a comentar la posibilidad de fomentar la intervención de la embajada norteamericana. El Laborista, por su parte, planteaba que la única solución era la intervención del Estado en la empresa. Según este periódico, su posición era de intransigencia hacia los obreros y de "franco alzamiento e insolencia frente a las autoridades nacionales". ${ }^{9}$ Esta situación no hacía

7. El Laborista, 12/05/46, y La Hora, 13/05/46. El primero de estos periódicos era editado por el ala político-sindical del peronismo. El segundo, era órgano del Partido Comunista Argentino.

8. El Laborista, 20/06/46.

9. El Laborista, 22/06/46. 
más que aumentar el valor de sus grandes stocks; por eso, su actitud era calificada de sabotaje.

En el editorial de El Laborista del 24 de junio se afirmó en primer lugar la importancia de la lucha en pos de mejores condiciones de trabajo. Luego, se resaltó el enfrentamiento con el imperialismo y cierta tensión con el capitalismo en general. Pero, sobre todo, se planteó el vínculo entre defensa de la Nación, peronismo y conflicto social. El triunfo de la huelga sería el de la Nación frente a quienes se le oponían. La movilización obrera era caracterizada como un factor de progreso, tanto social como técnico; y en este sentido, también era importante que la victoria fuera rotunda. ${ }^{10}$

A lo largo del tiempo, los distintos planes de estabilización del gobierno irian chocando con este problema. En vastos sectores obreros, la lucha sindical era entendida como una defensa del propio peronismo, incluso como un factor de progreso para la nación. El conflicto laboral estaba subsumido en el conflicto político gobierno-oposición, en la dicotomía peronismo-antiperonismo (Sidicaro, 1998). Resignificar la conflictividad que lo había acompañado desde su origen fue uno de los mayores propósitos que se fijó la gestión de Perón.

E1 25 de junio, con la intervención de Perón y el Ministro del Interior, Ángel Borlenghi, se llegó a un acuerdo entre la empresa y la AOT. Se solucionaba un conflicto que llevaba más de cuarenta dias. Tanto el periódico peronista como el comunista consideraron el fin de la huelga y el acuerdo como un triunfo pese a las reivindicaciones que aun quedaban sin lograr, muchas de ellas de gran importancia. ${ }^{11}$

La participación de Mariano Tedesco y de la AOT en la huelga de Sudamtex fue central. Al ser la mayoría de los fundadores del sindicato trabajadores de esta empresa, era necesario que se alcanzara una victoria que lo asentara, que le diera prestigio en las demás plantas textiles.

El caso de Sudamtex demuestra el peso que tenían las organizaciones en los lugares de trabajo del mundo textil a comienzos del peronismo, ya fueran estas comisiones internas o sindicatos autónomos, y cómo influyeron en el armado general del sindicato. También señala lo duro del conflicto capital-trabajo, más allá del apoyo del gobierno. La lucha por mejores condiciones de trabajo y por el reconocimiento del sindicato en la planta constituyeron los motores del conflicto textil en $1946 \mathrm{y}$ 1947. Esto, sin embargo, no podía mantenerse en el tiempo si el objetivo final del gobierno era regular y canalizar la movilización obrera. En este sentido, el caso de Argos en 1947 fue un primer llamado de atención.

10. El Laborista, 24/06/46.

11. El Laborista, 27/06/46, y La Hora, 27/06/46. 


\section{Argos y el Sindicato de Obreros Textiles Unidos}

Tal como adelantamos al comienzo de este artículo, la AOT no fue hasta 1949 el único sindicato del gremio textil. Éste es un hecho que la literatura sobre el tema no menciona. A partir de 1946, compitieron por la representación sindical distintas organizaciones que se reivindicaban como peronistas: el Sindicato de Obreros Textiles Unidos (SOTU) y la Federación Obrera Textil Argentina (FOTA) son los dos casos más importantes. En un panorama textil con plantas fabriles grandes sin agremiar o con sindicatos autónomos, la movilización y la combatividad de los sindicatos por rama impactaban en sus posibilidades de sumar adherentes. El conflicto desatado en la empresa lanera Argos de Valentín Alsina a mediados de 1947 confirmó las tensiones intersindicales que generaba esta situación.

El 21 de marzo de 1947, la comisión interna, adherida al SOTU, presentó a la empresa Argos un petitorio, firmado un mes y medio después, que incluyó diversas mejoras que, en algunos casos, superaban el $10 \%$ de aumento salarial. El inconveniente surgió transcurridos cuatro días de la firma, cuando la Cámara Argentina de la Industria Textil (Subrama Lana) propuso un agregado al convenio vigente en lana que incluía un suplemento transitorio de $\$ 0,25$ por hora para los hombres mayores de 22 años. Este incremento podía ser absorbido por aumentos anteriores, y eso fue lo que intentó realizar la empresa. Su propuesta era reconocer el nuevo monto, pero dejar de hacerse cargo del aporte jubilatorio del 8\% tal cual lo venía haciendo. Este punto llevó a discusiones que derivaron, a fines de mayo, en la resolución obrera de paralizar las acciones y tomar la fábrica. ${ }^{12}$

A mediados de junio, el sindicato comunicó que cesaba la huelga (había sido declarada ilegal por el gobierno) y que se aguardaría el arbitraje de la delegación regional de la STyP en Avellaneda en relación con el $8 \%$ de los aportes jubilatorios a cargo de la empresa. Cuando la STyP finalmente confirmó que el aporte debía ser realizado por los obreros, el SOTU decidió desconocer el laudo y declarar, el 23 de junio, la iniciación del trabajo a desgano. ${ }^{13}$

Diez días después, la STyP nuevamente declaró ilegal la medida. El SOTU definió la medida como un fallo arbitrario. Se enfrentaba así a la delegación estatal, complicando aún más su situación. A esto se sumarian luego las tensas relaciones con la AOT, que buscaba atraer hacia su organización a los trabajadores de Argos.

Durante el tiempo en que la policía recorrió las distintas secciones y

12. La Época, 04/06/47.

13. La Hora, 24/06/47. 
permaneció junto a los obreros mientras trabajaban, la empresa despidió al secretario general y a la totalidad de los miembros de la comisión interna. El 11 de julio, todo el comercio de Valentín Alsina cerró sus puertas en solidaridad con los trabajadores de Argos y pararon por veinticuatro horas todos los trabajadores textiles del partido de 4 de junio (Lanús); entre ellos, se encontraban aquellos ocupados en empresas del tamaño de Campomar y Teubal.

En la segunda semana de julio, la patronal dispuso la clausura de la fábrica y la suspensión por tiempo indeterminado de todo el personal hasta tanto los trabajadores no proporcionaran seguridades de que las tareas se realizarian normalmente. La medida afectaba a tres mil obreros. En una nueva solicitada, la empresa describia este hecho como "fruto de una minoría que agresivamente impedia a la mayoria trabajar" ${ }^{14} \mathrm{y}$ denunciaba el intento de este pequeño grupo de dirigentes de imponer salarios diferenciales a los uniformemente establecidos para la totalidad de la rama de la lana.

La empresa había cerrado sus puertas. El SOTU había decretado una huelga que no era apoyada por la STyP. La Época, por su parte, pedía que se levantase la medida, ya que "el país reclama menos huelgas y más trabajo". ${ }^{15}$

El punto clave del conflicto residía en que reconocer las reivindicaciones de los obreros de Argos implicaba romper con la homogeneidad salarial, por lo menos en la rama lana. Esto sería un duro golpe tanto para el gobierno como para el sindicato mayoritario. Lo era para la política gubernamental de regulación del conflicto y equilibrio salarial, y también para la AOT, cuyos representados pasarian a ganar menos que los del SOTU.

A comienzos de agosto, por medio de telegramas, la empresa citó a todos los obreros para que retomaran el trabajo; anunciaba, al mismo tiempo, que abría sus puertas nuevamente. Pese a que la policía garantizó la libertad de trabajo, pocas decenas de obreros se presentaron. No obstante, se produjeron incidentes entre los piquetes de huelguistas y los que entraban, que derivaron en la intervención policial y la detención de un número importante de integrantes del primer grupo. Esta represión incluyó la clausura del local del SOTU, aunque la medida fue dejada sin efecto rápidamente. ${ }^{16}$ Los factores políticos e intrasindicales empezaban a tensionarse por la prolongación del conflicto. Para la segunda semana de agosto, en La Época, directamente se caracterizaba la medida como una maniobra comunista. Mientras tanto, la postura de la AOT era ya de

14. La Época, 15/07/47.

15. La Época, 25/07/47.

16. La Época, $11 / 08 / 47$ y 12/08/47. La Hora, 10/08/47 y 12/08/47. 
claro enfrentamiento con el SOTU; incluso denunciaron que miembros del sindicato habian baleado en Valentín Alsina un camión en el que viajaban varios de sus militantes.

El 19 de agosto se publicó una carta de Lucio Cano, por entonces secretario general de la AOT. Fue el comienzo de un intercambio de notas en las que se discutió con intensidad, entre otras cosas, la legitimidad del modelo sindical peronista. En ella, Cano afirmaba:

En el mes de septiembre de 1946, entre la AOT y la CAIT, ante la STyP, se firmó un convenio de la rama lana, para toda la industria del país, convenio éste que para llegar a su finalización tuvo la AOT que efectuar paros parciales en todos los establecimientos de la rama. Estos paros se iniciaron con dos horas diarias y fueron en aumento hasta llegar a cuatro horas por día. En ese entonces, el único establecimiento textil que no efectuó dicho paro fue Argos. En pago a esa traición, la patronal pagó el $8 \%$ voluntariamente. ${ }^{17}$

La carta cerraba con un llamado a la cordura y propugnaba la vuelta al trabajo en la fábrica. Tres días después, el SOTU contestó la nota de la AOT. Firmaba el texto Alfredo Insúa, su secretario general, y toda la comisión directiva. Denunciaron que, en el conflicto del año anterior, la AOT había acordado con los industriales simular paros parciales para engañar a los trabajadores y así atraerlos hacia la AOT, "copando el movimiento iniciado por nosotros y posesionándose de las directivas del sindicato". Además, la AOT no había consultado acerca del convenio presentado ni respetado uno anteriormente confeccionado por el SOTU. Por eso, sus dirigentes habian resuelto no participar del paro de 1946. En relación con la firma del nuevo aumento salarial acordado y los inconvenientes que esto había generado en Argos, el texto planteaba que, al no ser el SOTU parte firmante, no se le podian imponer cláusulas perjudiciales. ${ }^{18}$

En su respuesta, Cano reafirmaba el derecho de la AOT para negociar en representación de todos los trabajadores textiles, estuvieran o no afiliados al sindicato:

[...] sobre el anteproyecto de convenio presentado en Avellaneda en el mes de abril de 1946 [por el SOTU] será cierto que ellos lo hayan presentado, lo que sí podemos afirmar todos los dirigentes y el decreto 23.852, que los únicos que tienen derecho a peticionar en forma colectiva son las asociaciones

17. La Época, $19 / 08 / 47$.

18. La Época, 22/08/47. 
con personería gremial, que se les concede después de haberse comprobado que tienen la mayoría de afiliados dentro del gremio. Esta mayoría en aquel entonces de la AOT, que contaba con sesenta mil afiliados contra seis mil que contaba el SOTU. [...] La AOT no consultó al SOTU porque no recibimos directivas de nadie que no sean nuestros afiliados. [...] Si bien es cierto que primero fue fundado el SOTU que la AOT preguntamos nosotros: ¿Por qué la AOT llegó a agrupar a noventa mil afiliados? Y, ¿Por qué al SOTU le queda un resto de dos mil afiliados? ${ }^{19}$

E1 SOTU se mantenía como sindicato autónomo no reconocido y por eso no podía firmar acuerdos a nivel rama. Su existencia se sustentaba, entonces, en el diferencial que podia alcanzar en las plantas donde representaba a la mayoría de los trabajadores, a través de firmas particulares y privadas. En una nueva nota, el SOTU afirmaba:

En lo que respecta a los noventa mil afiliados que dice haber agrupado la AOT se debe a la gran colaboración prestada por algunos funcionarios de la STyP que llegaron hasta el hecho insólito de concurrir a un establecimiento textil cuyo personal está afiliado a este sindicato y obligarles a afiliarse a la AOT para solucionarle un conflicto. ${ }^{20}$

Pese a las denuncias de La Época, éste no era un sindicato comunista. En realidad, parecía responder a una vieja herencia sindicalista de autonomía. Muchas fábricas del sur del conurbano bonaerense estaban en posiciones semejantes.

Finalmente, el 8 de septiembre de 1947 los periódicos informaron sobre la resolución del conflicto, que incluyó la reincorporación de los doscientos cincuenta trabajadores despedidos, la garantía horaria de mil seiscientas horas mensuales (el único establecimiento de la rama que gozaba de este beneficio), el 50\% de las horas perdidas en caso de deficiencias técnicas, y aumentos salariales por encima del convenio que equiparaban el importe del $8 \%$ que se venía reclamando. ${ }^{21}$

Este triunfo, sin embargo, no implicó un fortalecimiento del SOTU, que comenzó a decaer tiempo después. El modelo sindical peronista tendía fuertemente a la centralización. En el caso textil, demoró más tiempo, pero se logró aunque con resultados mucho menos satisfactorios que, por ejemplo, en el sector metalúrgico (Schiavi, 2012). La lucha

19. La Época, $27 / 08 / 47$.

20. La Época, 03/09/47.

21. El Laborista, 08/09/47. 
intersindical potenciaba el conflicto y negociación por empresa; esto, con el correr del tiempo, fue reprimido tanto por el gobierno como por el propio sindicato.

\section{Conflicto y sindicalización en Alpargatas}

El estudio en profundidad de la conflictividad y la sindicalización en Alpargatas merece especial atención por su importancia económica y sindical. Durante la década peronista, la Fabrica Argentina de Alpargatas fue una de las empresas más grandes del país (Gutiérrez y Korol, 1988; Ceva, 2010). Sin duda, la mayor de las textiles algodoneras. Ocupaba alrededor de diez mil obreros, cerca del $10 \%$ del total de la actividad. Era dominante en la industria y clave en el gremio: lo que ocurría allí impactaba en toda la subrama algodón. Esta gigantesca fábrica estaba ubicada en el barrio de Barracas, en el corazón industrial de la ciudad de Buenos Aires, rodeada de frigoríficos y empresas metalúrgicas $(\mathrm{Be}-$ lini, 2009).

Alpargatas condensa los tres problemas fundamentales del período 1946-1947, adelantados en los apartados anteriores: los conflictos en la planta por el reconocimiento de la organización sindical, la búsqueda de mejoras en las condiciones de trabajo y el vínculo entre militancia por empresa y sindicalización por rama. En primer lugar, demuestra que el reconocimiento de las comisiones internas fue un proceso arduo, que contó con una persistente resistencia patronal, un apoyo relativo del gobierno, y que dependió de la movilización constante de las bases obreras. En segundo lugar, en estos primeros tiempos, los trabajadores textiles (en este caso, los de Alpargatas) lograron imponer límites a ciertas prerrogativas empresarias y ganaron poder en sus plantas, incluso por fuera de los convenios colectivos por rama. Por último, la conformación del sindicato único textil fue un camino largo en el que la organización por empresa cumplió un papel clave.

Durante años, había sido considerada una fábrica modelo, en la que convivian modernos métodos de producción con formas paternalistas de manejo del personal, sueldos superiores al promedio de la actividad y una firme política antisindical. Pese a esto, a las persecuciones y listas negras, en los años 20 y 30, los comunistas habian logrado constituir células obreras, aunque sin llegar a conformar comisiones internas (Camarero, 2007; Ceruso, 2010). Recién en 1944, en septiembre, se había formado la Federación Gremial Alpargatas. Sin embargo, y pese a que la STyP había asegurado que evitaría las represalias, su presidente y varios obreros fueron despedidos por la dirección. Con esos despidos les bastó para desarticular esta experiencia.

Un año y medio después, el clima político posterior al 17 de octubre 
de 1945 no le permitía a la empresa reprimir de manera tan eficaz. A fines de enero de 1946 se conformó la Comisión Provisoria del Sindicato y Mutual del Personal de la Fábrica Argentina de Alpargatas. De clara vinculación comunista, este sindicato llamó inmediatamente a una asamblea y comenzó a confeccionar un programa de mejoras que incluía, en primer lugar, la humanización del trabajo standard. ${ }^{22}$

En marzo, en una nueva asamblea, se resolvió por mayoría la afiliación del sindicato a la AOT en carácter de comisión interna y el nombramiento de una nueva dirección a cargo de Antonio Príncipe y Andrés López. Al pasar de ser sindicatos por empresa a comisiones internas, ganaban la protección del sindicato nacional reconocido por la STyP, pero perdía libertad. Como era de esperar, la empresa se negó a reconocer la organización sindical, lo que provocó reiterados conflictos a lo largo de 1946.

El primero de esos ceses de actividades se produjo a comienzos de abril. El 9 de ese mes, la STyP informó que había quedado resuelto el conflicto porque la empresa habia reconocido a la AOT como representante gremial de su personal. Per se, eso no solucionaba el conflicto, pues quedaba pendiente el problema de los despedidos. Un día después, se realizó una asamblea para decidir si se levantaba el paro o no, cuestión que finalmente se hizo. Andrés López, miembro de la comisión interna, comenzó la asamblea destacando la fuerza y la unidad de la medida. Un representante de la AOT afirmó: "En adelante todos deben permanecer unidos, sin diferencias de ninguna clase: comunistas, peronistas, socialistas, para defender sus intereses de clase". ${ }^{23}$ Estos hechos no implicaron el reconocimiento definitivo, ya que los acuerdos a los que se llegaba eran inestables. Incluso, el apoyo del gobierno parecía no alcanzar. $^{24}$

El siguiente enfrentamiento fue en mayo y se debió a que la empresa pretendió digitar los miembros de la comisión interna para asegurarse que ésta fuera un canalizador del conflicto, que lo regulase y no que lo motorizase. Se oponía a los elegidos por los trabajadores en una asamblea de dos mil obreros realizada el 12 de mayo, lo que, en los hechos, significaba dejar de reconocer la organización. Ante la oposición patronal, el 23 de mayo de 1946, la STyP debió dictar una resolución en la que intimaba a Alpargatas a reconocer la comisión representativa de los obreros de su establecimiento. ${ }^{25}$ La intimación obligaba a la empresa a reconocer, en los tres días siguientes, la comisión interna nombrada

22. La Hora, 08/02/46, 15/02/46 y 18/02/46.

23. La Hora, $11 / 04 / 46$.

24. El Laborista, 14/04/46.

25. Revista Trabajo y Previsión, abril-mayo-junio de 1946, pp. 545-546. 
en asamblea el 12 de mayo. De lo contrario, su actitud podía ser considerada práctica desleal.

$\mathrm{El}$ tercer conflicto fue en julio. Su causa fue que, pese a la resolución oficial, la empresa siguió sin reconocer la organización sindical. En una nueva asamblea llevaba a cabo el 7 de julio de 1946, de los tres puntos que reclamaban los obreros, uno era el reconocimiento de la comisión interna. Los otros incluian la reincorporación de tres obreros despedidos y la reglamentación del trabajo en las secciones insalubres. Alli se aprobó la proposición de Andrés López (ahora secretario general) de realizar paros de brazos caídos parciales, los que comenzaron el jueves 11 de julio (una hora en los tres turnos). De no resolverse los inconvenientes planteados, la estrategia era continuar con la implementación de los paros y aumentar su duración un cuarto de hora por dia hasta llegar a la huelga (que se decidiría en asamblea general). ${ }^{26}$ Luego de cinco días de paros parciales, la empresa cedió ante las demandas exigidas: reconoció la comisión interna y reincorporó a los despedidos. Finalmente, Alpargatas aceptaba una comisión interna compuesta de cinco miembros, delegados de cada departamento y un subdelegado por cada sección y turno, los que, a su vez, dependerian de la AOT. ${ }^{27}$

Este reconocimiento no significó el fin de la conflictividad. Los trabajadores de Alpargatas buscaron imponer a la dirección de la empresa nuevas condiciones, mientras instancias superiores, tanto gubernamentales como sindicales, intentaban controlarlos. Durante la segunda semana de diciembre de 1946 comenzó una huelga de brazos caídos en la sección hilandería, que, luego de dos jornadas, se extendió a todos los establecimientos de la fábrica. Entre las causas del conflicto se encontraban incumplimientos y abusos patronales y nuevos reclamos obreros. Fue una de las huelgas más prolongadas del periodo. ${ }^{28}$ Durante la segunda semana de enero, la huelga de brazos caídos, que durante veintiún días habían mantenido los obreros de Alpargatas, se transformó en una huelga total. La decisión de que el personal saliera a la calle para hacer más combativa la acción obrera había sido tomada por la AOT. Ante esta situación, a mediados de mes la empresa volvió a negociar. El 18 de enero ya había un acuerdo parcial que contemplaba el pago de limpieza de máquinas; el establecimiento de una comisión paritaria para discriminar las tareas; la formación de juntas médicas para estudiar el problema del rendimiento físico, que estarian integradas por un delegado de Salud Pública, un representante obrero y otro patronal; la realización de una pericia con respecto a las rebajas de salarios; y los

26. El Laborista, 12/07/46 y 13/07/46.

27. El Laborista, 18/07/46, y La Hora, 18/07/46.

28.La Hora, 05/01/47, y La Época, 05/01/47. 
cambios de secciones en los casos en que el trabajo afectara fisicamente a los obreros. El 22 de enero, luego de más de cuarenta días de conflicto, se aprobó el convenio en asamblea.

Con esta firma, en menos de dos años, la comisión interna de Alpargatas lograba establecerse como una de las organizaciones clave del gremio textil, del cual representaba alrededor de un $10 \%$. Primero, la constante movilización y las distintas medidas de fuerza habian obligado a que la empresa la reconociera. Una vez asentada, su objetivo fue lograr mejores salarios y condiciones de trabajo para los obreros y obreras de Alpargatas. Esto impactó no solo en la fábrica, sino que marcó parámetros en la rama algodón y en la industria textil en su conjunto.

\section{Intervención, unión y crisis del gremio textil}

E1 24 de octubre de 1947, luego de una huelga general textil de algo menos de una semana, la Confederación General del Trabajo nombró una comisión de conciliación de la AOT presidida por delegados de la central, lo cual era un claro eufemismo. Esta comisión hizo público un manifiesto a través del cual pretendía hacerles saber a sus asociados que debian mantener estricta disciplina y no dejarse influenciar por personas extrañas a los intereses del gremio. También se informó que la AOT no estaba intervenida, sino que se había constituido una comisión de conciliación presidida por delegados de la CGT, cuyo objetivo era reorganizar el sindicato y su padrón para llamar a elecciones rápidamente (las cuales se realizaron recién un año después). El documento concluía exhortando a mantener la unidad gremial y a sostener el ritmo de trabajo. ${ }^{29}$

Esta intervención no sólo fue en el campo dirigencial, no se circunscribió a desplazar a Lucio Cano, sino que también implicaba alcanzar un mayor control sobre las seccionales y comisiones internas. Siguiendo el camino recorrido en otros casos, a comienzos de diciembre de 1947 el interventor Cecilio Conditti logró imponer un veedor en Alpargatas, lo que significaba una intervención encubierta. Horas después, este veedor citó a un delegado de sección y le pidió que renunciara, ya que, como era comunista, no estaba identificado con la política oficialista. ${ }^{30}$

Concluida la intervención en noviembre de 1948, el período 19491952 significó para la AOT una etapa de normalización y de confirmación como sindicato único de la rama. El $1^{\circ}$ de noviembre de 1948 culminaron las elecciones del sindicato. Hubo en ellas cuatro listas: la Azul, encabezada por Antonio Ciurlande, quien había sido recientemente designado

29. La Prensa, 25/10/47.

30. La Hora, 04/12/47. 
para asistir a la Conferencia Internacional del Trabajo en Ginebra; la Marrón, a cuyo frente estaba Andrés Framini; la Amarilla, de Mariano Tedesco; y la Verde, de Miguel Figueroa. En total, votaron dieciocho mil afiliados. Resultó ganadora la lista Azul, por lo que fueron elegidos Ciurlande, secretario general; Julio Barbiero, secretario adjunto; José Luis Grioli, secretario administrativo; y Antonio Hermida, tesorero. Gran parte de la dirigencia anterior volvía a encabezar el sindicato. Mariano Tedesco y Lucio Cano, los dos secretarios generales que había tenido la AOT, quedaron afuera. ${ }^{31}$

La unificación fue decidida en el Cuarto Congreso Nacional y Segundo Extraordinario de la FOTA, llevado a cabo a comienzos de junio de 1949 en Quilmes (Buenos Aires). ${ }^{32}$ Días antes de su realización, en la prensa peronista se había resaltado que era factible que las filiales convocadas por la federación aprobaran el plan de unidad gremial elaborado conjuntamente por directivos de la FOTA y la AOT. Finalmente, y tal como se esperaba, fueron aprobadas en el Congreso las bases de la unidad. La FOTA pasaba a formar parte de la AOT, también sus fondos y todo otro patrimonio. No se sumaba a una confederación (como había sido pensado en su momento con la Confederación Obrera Textil de la República Argentina), sino que era absorbida por la asociación textil. Tres miembros de la FOTA integrarian el secretariado y el consejo directivo de la AOT. Al acto de clausura del Congreso asistieron María Eva Duarte de Perón y Domingo Mercante, lo que demostraba su trascendencia. ${ }^{33}$

Este desarrollo organizacional se dio en paralelo a una importante crisis económica, que impactó tanto a nivel político como social, y particularmente en el mundo textil. La dinámica sindical no fue ajena a este cimbronazo. Desde la lógica dirigencial y del gobierno, era necesario mantener niveles de conflictividad bajos, en medio de la crisis. En la AOT, los dirigentes optaron por la paz social y el resguardo del empleo. Sin embargo, este intento de control no fue completamente exitoso.

La movilización de base fue muy difícil de frenar. Esto tenía tanto que ver con la herencia de los sindicatos autónomos como con el desigual poder entre unas pocas empresas enormes y estratégicas, y muchas pequeñas y dependientes. Así, mientras el sindicato acordaba convenios por rama y limitaba aumentos salariales, en ciertas empresas, pese al clima represivo, la movilización presionaba e imponía condiciones, lo que debilitaba a la AOT y su búsqueda de centralizar la negociación.

En Piccaluga, por ejemplo, a mediados de 1949, se habia conseguido un incremento salarial por fuera del convenio acordado. En medio

31. La Época, $01 / 11 / 48$.

32. La Época, 04/06/49.

33. La Época, 07/06/49. 
de las negociaciones entre delegados obreros y patrones, la AOT había presionado a estos últimos para que no cediesen, pese a lo cual se había firmado el aumento. Luego de esto, la comisión interna había quedado fuertemente enfrentada a la dirigencia del sindicato. Por eso, a fines de septiembre de 1949, la AOT informó a la empresa que la comisión interna quedaba intervenida y sus integrantes, inhabilitados por dos años. ${ }^{34}$ De esta manera, la dirigencia textil buscaba frenar los reclamos económicos independientes, porque golpeaban directamente su proyecto de consolidación institucional.

La represión interna integraba un proyecto más amplio de conformación de una AOT compacta y estable. En cierta medida, sus dirigentes tuvieron éxito; se pudo disciplinar el aparato sindical y gran parte de las comisiones internas. El problema fue que esto puso en discusión la capacidad de la propia AOT para canalizar el conflicto y los reclamos obreros. Finalmente, la debilitaba dentro del gremio y en sus negociaciones con los industriales, pues no estaba en condiciones de hacer respetar los acuerdos firmados.

Muestra de esto es que a fines del primer gobierno de Perón, en el mayor pico de la crisis económica y con el poder del sindicato menguado, se produjeron múltiples microconflictos en las plantas. Algunos fueron organizados por las comisiones internas; otros, en cambio, a través de diferentes carriles. Los más importantes se dieron a comienzos de 1952, y en defensa de los puestos de trabajo. En ciertos casos, al plantear la patronal el cese de actividades generales, los obreros tomaban espontáneamente las fábricas, y llegaron, incluso, a mantener la producción en marcha. En Teubal, de Valentín Alsina, la empresa había suspendido por un mes a gran parte del personal, ante lo cual, en una asamblea el 5 de marzo, se resolvió presentarse en los tres turnos el lunes 7 en la fábrica. Reunidos ese día en la puerta, decidieron entrar y seguir trabajando, desconociendo, de esta manera, el telegrama de suspensión. Desde ese día, en ausencia de jefes y patrones, el personal continuó su labor. ${ }^{35}$ Tiempo antes, en La Bernalesa (Quilmes) había sucedido algo semejante.

Al afectar con mayor intensidad la actividad textil, la situación económica socavó rápidamente el poder sindical que la AOT buscaba consolidar. Su dirigencia fue condescendiente con el sector patronal, y aceptó medidas pro racionalización y productividad. Se veía más comprometida con el mantenimiento de los niveles de empleo que con las mejoras en las condiciones de trabajo. Todo esto, la crisis de representatividad de la dirigencia y el mayor control sobre las comisiones internas, llevó a

34. A los obreras y obreros de Piccaluga. 1949.

35. Nuestra Palabra (órgano oficial del Partido Comunista), 25/03/52. 
que parte del conflicto textil se canalizara por fuera del sindicato. Esta era la situación al terminar el primer mandato del peronismo.

\section{A modo de cierre}

Las marcas de origen del gobierno peronista, aquellas que mencionamos en el primer párrafo de este artículo, determinaron en gran medida los límites y las posibilidades del gobierno puesto en marcha el 4 de junio de 1946. El gobierno de Perón era consciente de las dificultades políticas que acarreaba la posición ganada por los sindicatos. Por eso, se propuso limitar y canalizar la movilización sindical, así como también menguar el poder político y social de las organizaciones obreras. En pos de lograr este objetivo, se disolvió el Partido Laborista, se propició el desplazamiento de Luis Gay de la CGT, y se reforzaron los llamados a producir más y a evitar conflictos laborales apenas iniciado el gobierno.

A comienzos de la década del 50, ya en momentos de crisis económica, el presidente de la Nación solicitó a los dirigentes sindicales coherencia entre el compromiso político y las reivindicaciones económicas; les pedía responsabilidad, una mejor organización y control de los sindicatos. La cuestión por resolver era si podian hacerlo y con qué consecuencias.

Es necesario resaltar aquí que, tal como demuestra este trabajo y otros (Schiavi, 2012; Contreras, 2007), la adhesión política de los trabajadores no equivalia a una ciega disciplina, sobre todo en los lugares de trabajo. Pocas huelgas durante el peronismo contaron con el fomento directo del gobierno: la mayoría fueron impuestas por la movilización obrera. Esa capacidad sindical tenía en la situación política su condición de posibilidad, pero, a su vez, dependía de elementos particulares, de la dinámica de cada organización y del lugar que ocupaban sus representados en la economía nacional.

Junto con estos elementos, dos factores generales justificaban esta movilización. Por un lado, el conflicto laboral estaba subsumido en el conflicto político gobierno-oposición. El problema con el que chocaban los proyectos de estabilización y racionalización productiva residia en que, para vastos sectores obreros, la lucha sindical era entendida como una defensa del propio peronismo (o de lo que el peronismo significaba para ellos). Por otro lado, en un breve período, se había generado un sentido común obrero en el que ocupaba un lugar central la idea de que el poder les pertenecía, ya fuese en el ámbito estatal o en la planta (con las comisiones internas y los convenios colectivos como principal arma). Contra esto, también debían luchar los planes patronales y del gobierno.

El caso analizado en este artículo refuerza estas afirmaciones. E1 sindicato textil se formó en base a la movilización de los trabajadores 
en los lugares de trabajo. El apoyo estatal fue clave, pero la fisonomía de la AOT se la dieron las comisiones internas que se multiplicaron y engrosaron la joven organización.

Con el correr del tiempo y la consolidación del gobierno y las dirigencias sindicales, esta situación buscó ser controlada. Este proceso, uno de cuyos mojones más importante fue la intervención de 1947, intentó fortalecer la organización estableciendo controles más estrictos. No obstante, ese mayor control y la persecución de militantes sindicales no implicaron el cese del conflicto. Fue muy dificil desandar el camino de los años anteriores.

El desafio de la nueva dirigencia textil una vez normalizado el sindicato en 1948 fue continuar esa linea. Lograron, en plena crisis, evitar altos niveles de conflictividad, pero a un precio muy alto. No pudieron afianzarse, poniendo en riesgo su propio lugar. Un tiempo después, serian desplazados por una nueva dirigencia, la Lista Verde de Andrés Framini.

\section{Bibliografia}

Acha, O. (2004), "Sociedad civil y sociedad política durante el primer peronismo", Desarrollo Económico, 44, 174.

Baily, S.L. (1985), Movimiento obrero, nacionalismo y politica en la Argentina, Buenos Aires: Hyspamérica.

Basualdo, V. (2010), Labor and structural change: shop-floor organization and militancy in Argentine industrial factories (1943-1983), tesis doctoral, Columbia University, 2010.

Belini, C. (2009), La industria peronista: 1946-1955, politicas públicas y cambio estructural, Buenos Aires: Edhasa.

Camarero, H. (2007), A la conquista de la clase obrera. Los comunistas y el mundo del trabajo en la Argentina, 1920-1935, Buenos Aires: Siglo Veintiuno Editora Iberoamericana.

Ceruso, D. (2010), Comisiones internas de fábrica. Desde la huelga de la construcción de 1935 hasta el golpe de estado de 1943, Buenos Aires: PIMSA.

Ceva, M. (2010), Empresas, trabajo e inmigración en la Argentina. Los casos de la Fábrica Argentina de Alpargatas y la Algodonera Flandria, 18871955, Buenos Aires: Biblos.

Contreras, G.N. (2006), "El peronismo obrero. La estrategia laborista de la clase obrera durante el gobierno peronista. Un análisis de la huela de los trabajadores frigoríficos de 1950", PIMSA.

Crouch, C., y A. Pizzorno (comps.) (1991), El resurgimiento del conflicto de clases en Europa Occidental a partir de 1968: II, Madrid: Ministerio de Trabajo y Seguridad Social. 
Del Campo, H. (1983), Sindicalismo y peronismo. Los comienzos de un vínculo perdurable, Buenos Aires: CLACSO.

Di Tella, T.S. (1993), "La Unión Obrera Textil, 1930-1945”, Desarrollo Económico, 33, 129.

Doyon, L.M. (2006), Perón y los trabajadores. Los origenes del sindicalismo peronista, 1943-1955, Buenos Aires: Siglo Veintiuno.

Gambini, H. (1999), Historia del peronismo, Buenos Aires: Planeta.

Germani, G. (1962), Politica y sociedad en una época de transición. De la sociedad tradicional a la sociedad de masas, Buenos Aires: Paidós.

Gilly, A. (1986), "La anomalía argentina", Cuadernos del Sur, 4.

Gutiérrez, L., y J.C. Korol (1988), "Historia de empresas y crecimiento industrial en la Argentina. El caso de la Fábrica Argentina de Alpargatas", Desarrollo Económico, 28, 111.

Horowitz, J. (2004), Los sindicatos, el Estado y el surgimiento de Perón: 19301946, Caseros: Universidad Nacional de Tres de Febrero.

Iñigo Carrera, N. (2000), La estrategia de la clase obrera, 1936, Buenos Aires: La Rosa Blindada.

James, D. (1981), "Racionalización y respuesta de la clase obrera: contexto y limitaciones de la actividad gremial en la Argentina", Desarrollo Económico, 21, 83.

Little, W. (1979), "La organización obrera y el Estado peronista, 19431955”, Desarrollo Económico, 19, 75.

Montgomery, D. (1985), El control obrero en Estados Unidos. Estudios sobre la historia del trabajo, la tecnologia y las luchas obreras, Madrid: Ministerio de Trabajo y Seguridad Social.

Offe, C. y H. Wiesenthal (1985), "Dos lógicas de la acción colectiva", Cuadernos de Sociología UBA, 3.

Schiavi, M. (2012), La dinámica sindical durante los dos primeros gobiernos peronistas (1946-1955). El caso de las industrias metalúrgica y textil en la Ciudad de Buenos Aires y sus alrededores, tesis de doctorado, Universidad de Buenos Aires-Université Paris VIII.

Sidicaro, R. (1998), "Consideraciones sociológicas sobre las relaciones entre el peronismo y la clase obrera en la Argentina, 1943-1955", en M. Mackinon y M. Petrone, Populismo y neopopulismo en América Latina. El problema de la Cenicienta, Buenos Aires: Eudeba.

Torre, J.C. (1990), La vieja guardia sindical y Perón. Sobre los orígenes del peronismo, Buenos Aires: Sudamericana.

Villanueva, J. (1972), "El origen de la industrialización argentina”, Desarrollo Económico. 12, 47.

Resumen: La conflictividad industrial a comienzos del gobierno peronista impactó, por un lado, a nivel organizativo pues fue determinante en la conformación de 
los nuevos sindicatos industriales. Por otro, en la relación capital-trabajo, ya que las victorias obreras transformaron condiciones de trabajo. Este entrelazamiento entre movilización y organización consolidó los nuevos sindicatos industriales. En textiles, en 1946 y 1947, pese a que las negociaciones se efectuaban por subrama, una parte importante de los conflictos se desarrolló por empresa. Esto fue una de las particularidades de la rama en los primeros tiempos peronistas y fue clave en la conformación de la Asociación Obrera Textil.

Aquí se analiza esta etapa a partir de tres casos, para luego describir sucintamente el proceso de control de las organizaciones de base, generalizada a partir de fines de 1947.

Palabras claves: peronismo - textiles - organización - conflicto

Abstract: Industrial unrest in the early impact of the Peronist government, on the one hand, at the organizational level as was decisive in the formation of the new industrial unions. On the other hand, in the capital-labor ratio, because the workers' victories transformed conditions of work. This interweaving between mobilization and organization consolidated the new industrial unions. In textiles, in 1946 and 1947, despite the fact that the negotiations were conducted through sub-branch, an important part of the conflict was developed by company. This was one of the particularities of the branch in the early days peronists and was key in shaping the Textile Labor Association.

This article explores this stage from three cases, and then briefly describe the process of controlling the grassroots organizations, generalized from late 1947.

Keywords: peronism - textiles - organization - conflict

Recepción: 27 de diciembre de 2012. Aprobación: 9 de febrero de 2013. 